education and care in a developing country - ILAR Initiative. Clin Rheumatol $2013 \mathrm{Nov;32(11):1669-71}$

Disclosure of Interest: None declared

DOI: 10.1136/annrheumdis-2018-eular.2244

\section{AB1255 A REVIEW OF CASE-MIX AND CENTRE EFFECT ADJUSTMENT IN EARLY RHEUMATOID ARTHRITIS COHORTS}

M. Yates, K. Bechman, S. Norton, J. Galloway. Academic Rheumatology, King's College London, London, UK

Background: Observational cohort studies have been utilised extensively in early Rheumatoid Arthritis (RA), regularly conducted across multiple centres spanning regional and national boundaries. Case-mix and centre effect are considerations essential for determining comparability of results, and likely prevalence of bias. There is currently no standardised approach for case-mix and centre effect adjustment in early RA observational cohorts.

Objectives: Describe the spectrum of methodologies used to address case-mix and centre level effects on outcomes in multi-centre early RA observational cohort studies.

Methods: Inclusion criteria were cohorts recruiting from 2 or more centres with 100 or more subjects, with a Rheumatologist diagnosis of RA or EIA within the last 24 months. A systematic electronic search of publications was undertaken. Papers were reviewed by two researchers independently. Reference lists of included papers were reviewed for further relevant publications. A search of all included papers' authors was also conducted. Detail on cohort characteristics, case-mix data collection and adjustment, and consideration of centre-level effect in analyses were collected.

Results: 1047 papers were identified from the initial search. A total of 20 unique cohorts were identified. Reference review and author search produced 14 more, to make a total of 34 unique observational cohorts drawn from 205 papers. The cohorts were mainly conducted in Europe (24/34, 71\%), With 2 (6\%) from less economically developed regions. The period of data collection was between 1955 and 2017.

Case-mix: All cohorts considered case-mix in some form (e.g. age and gender), but with heterogenous approaches. The figure displays the relative frequencies of sociodemographic variable consideration across all included papers.

Centre effect: 18/205 (9\%) of the included papers accounted for centre in their results, utilising a range methodologies. Where reported, centre had a significant impact.

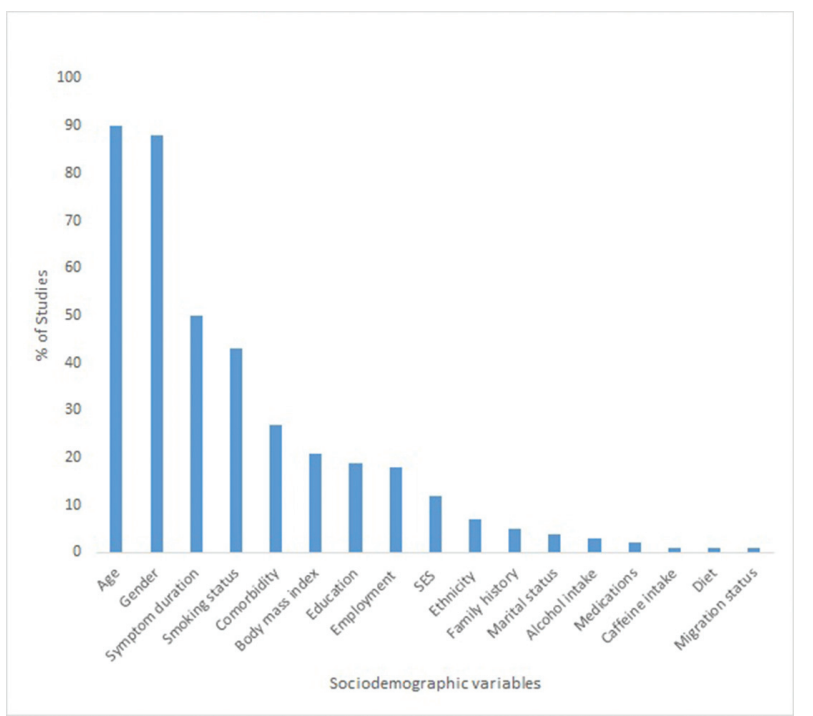

Abstract AB1255 - Figure 1

Conclusions: The degree of case-mix reporting varied widely, and few studies addressed centre effect. Where analysed, a centre level impact was clearly apparent. A failure to incorporate centre into analyses can lead to unrecognised bias as a result of confounding by centre. It must be acknowledged that including casemix variables and adjusting for centre substantially reduces power, and it is likely that many of the reported observations may have lost statistical significance had case-mix and centre effect been addressed more completely. This is the first systematic review of centre effect and case-mix in early RA, and highlights a challenging field deserving further research.

Disclosure of Interest: None declared

DOI: 10.1136/annrheumdis-2018-eular.1913

\section{AB1256 1 DEVELOPMENT OF A NATIONAL SERVICE FOR BIOLOGIC DRUG MONITORING}

M.E. Perry, on behalf of Effective Prescribing Programme Biologics Working Group, National Services Scotland. Rheumatology, ROYAL ALEXANDRA HOSPITAL, Paisley, UK

Background: Monitoring serum levels of biological drugs has well recognised benefits for patients and health services. These include appropriate dosing, avoidance of overtreatment, identification of drug failure due to immunogenicity, cost and facilitation of switching therapy. ${ }^{1}$

Objectives: To establish a national service for monitoring serum levels of biological drugs.

Methods: National Services Scotland established a working group comprised of clinicians, lead pharmacist and Director of Public Health to help optimise biological drug prescribing. (Effective Prescribing Programme Biologics -EPPB). It was recognised that ad-hoc biologic drug monitoring $(B M)$ posed a risk of variation in standards and inequity of access. Existing test volume and cost was established and a business case submitted to the CEO's of each Health Board in Scotland for a national service, testing adalimumab and infliximab twice yearly in 2265 patients. Potential cost savings based on drug withdrawl of $2.5 \%, 5 \%, 10 \%$, and $15 \%$ in gastroenterology patients ranged from 400,000 Euro to 3.5 million Euro. Additional savings for dose reduction in rheumatology patients were not costed but likely to incur further financial advantage.

Results: The case was accepted and service tendered. A single site in Glasgow will run the assays (purchased from Grifols) commencing December 2017. The cost modelling predicts a $50 \%$ reduction in cost per test compared to existing arrangements. Cost for the whole service will be divided between the commissioning Health Boards with outlay proportional to patient population. The EPPB developed specialty specific advice and an ordercomm with minimum datase accessible from all Health Boards with the option of retrospective interrogation. A national educational event is scheduled to improve clinician confidence and awareness.

Conclusions: To our knowledge this is the first national fully funded biologic drug monitoring service with access to all users of biological drugs. Its introduction will: 1. Support the implementation of national standards of care to ensure the effective and cost effective use of biologic medicines 2. Ensure equity of access to BM across Health Boards. 3. Provide a stronger position for procurement of biologic drugs (uncomplicated by additional service offerings) 4. Provide a sustainable service for Scotland, independent of the drug manufacturer.

\section{REFERENCE:}

[1] Jani, et al. Clinical Utility of Random Anti-Tumor Necrosis Factor Drug Level Testing and Measurement of Antidrug Antibodies on the Long-Term Treatment Response in Rheumatoid Arthritis. Arthritis and Rheumatology 67:8;(2015) p2011-2019.

Disclosure of Interest: None declared DOI: 10.1136/annrheumdis-2018-eular.2259

\section{$\mathrm{AB} 1257$ \\ IMPACT OF A SYSTEMATIC SCREENING OF MULTIMORBIDITIES IN PATIENTS WITH CHRONIC INFLAMMATORY RHEUMATIC DISEASES}

M. BEURAI-WEBER ${ }^{1}$, A. JAUSSENTA. JAUSSENT ${ }^{2}$, G.DU. CAILAR ${ }^{3}$, M.C. PICOT ${ }^{2}$, F. ROUBILLE ${ }^{4}$, J.-D. COHEN ${ }^{1}$, J. MOREL $^{1}$, J. BOUSQUET P. FESLER ${ }^{3}$, B. COMBE ${ }^{1}$, C. DAIEN ${ }^{1} .{ }^{1}$ Rheumatology Department, ${ }^{2}$ Department of medical information; ${ }^{3}$ Internal medicine and hypertension, Lapeyronie Hospital and Montpellier University; ${ }^{4}$ Department of cardiology, Arnaud de Villeneuve Hospital and Montpellier University, ${ }^{5}$ MACVIA-France, Lapeyronie Hospital and Montpellier University, MONTPELLIER, France

Objectives: EULAR proposes to screen multimorbidities in chronic inflammatory rheumatic diseases. The aim of the study was to assess i) multimorbidities in patients with chronic inflammatory diseases, ii) how patients follow recommendations given after a systematic standardised multimorbidity screening.

Methods: Exams were performed during a 1 day multimorbidity clinic. Diabetes, hypertension, CVD damage, chronic respiratory diseases, osteoporosis and preventive measures were assessed. Advice, complementary exams and prescriptions were provided to patient and general practitioner after this check-up if needed. Patients were called 3 months later to assess the applications of the given recommendations. 
Results: Among the 541 patients screened, hypertension was present in $28.1 \%$ patients, dyslipidemia in $19.2 \%$, chronic respiratory tract diseases in $12.8 \%$ and diabetes in $9.6 \%$. Screening led to the following recommendations: blood pressure monitoring (22.6\% patients), dietary advice $(56.8 \%)$, cardiologist referral $(35.5 \%)$, intensification of physical activity $(27.0 \%)$, cancer screening $(50.5 \%)$, vaccinations $(60.6 \%)$ and vitamino-calcium supplementation $(30.3 \%)$. On the 237 patients called back, $72.3 \%$ underwent blood pressure monitoring, $58.6 \%$ followed dietary advice, $64.4 \%$ took vitamino-calcium supplementation, $55.2 \%$ had vaccinations done, $52.1 \%$ saw a cardiologist, $42.7 \%$ increased physical activity and $31.4 \%$ performed cancer screening. No specific gender, age, pathology, or psychological factors were associated with adherence to recommendations.

Conclusions: This study underlines the relevance of a systematic screening of multimorbidities in chronic inflammatory rheumatic diseases, and the good patient's adherence rate to the recommendations.

Disclosure of Interest: None declared

DOI: 10.1136/annrheumdis-2018-eular.3756

\section{AB1258 EARLY ARTHRITIS SERVICE IS COST EFFECTIVE, IMPROVES OUTCOMES AND REDUCES BIOLOGIC USE}

G.A. Niazi, M.K. Nisar. Rheumatology, Luton and Dunstable University Hospital, Luton, UK

Background: There is good evidence that dedicated early arthritis clinics (EACs) improve referral lag time and reduce delay in establishing disease-modifying therapy. However it remains arguable whether such clinics improve relevant disease outcomes. Nationally, only $57 \%$ of units have dedicated EACs.

Objectives: We established Early Arthritis Service (EAS), centred on NICE RA quality standards, to reduce the time to diagnosis and the start of definitive therapy with an aim to accomplish good outcomes by the introduction of dedicated Early Arthritis Clinics (EACs).

Methods: The department set up an early arthritis service with introduction of six clinics (EACs) every week. An agreed treatment protocol incorporating ultrasound was developed to ensure standardised approach to early initiation of treatment, drug education and timely review. This is a retrospective study of all patients presenting to the service in the first year.

Results: Our catchment area covers a population of 350000 with $40 \%$ ethnic minorities. Of 1884 patients referred, 482 (25.5\%) were triaged into EACs based on set criteria. All were reviewed within 3 weeks. 247 (51\%) were confirmed to have early arthritis. Mean age was 52.4 years (17-86y). 157 (63.5\%) were women. 177 $(71.6 \%)$ were White, $58(23.5 \%)$ of Asian and twelve of other background. 159 $(64.3 \%)$ had RA, 57 (23\%) with PsA and 31 had other inflammatory arthritides. 25 $(10 \%)$ had erosions at presentation. There was median 26 weeks delay (0.41043 weeks) from symptom onset to GP presentation. Median time for GP referral to the department was 4.0 days (0-84 days). Mean DAS28 at first visit was 4.65 $(0.6-8.0, \mathrm{n}=166)$

$95 \%$ commenced their DMARDs within 3 week of initial review. Other $5 \%$ who missed the target was owing to patient factors. Treating to target achieved DAS28 remission for $84(53.5 \%)$ and low disease activity for a further $44(34 \%)$. Median time to achieve remission or LDA was 20 weeks ( $0-52$ weeks, $n=128)$. Similarly, $40 / 57(70 \%)$ of PsA patients achieved good PsARC response in median 24 weeks. Of 247 , only 21 ( $8.5 \%$ ) patients required escalation to biologic therapy. Conclusions: Dedicated EACs help achieve good clinical outcomes in majority of patients. Nearly $87 \%$ of our cohort attained remission or low disease activity in less than six months. This was despite a significant delay in patients presenting to their GPs and moderately-high disease activity. $100 \%$ of our patients were treated to target facilitated by protocol driven escalation of therapy in these clinics. This is in contrast to the national audit findings whereby only $68 \%$ of patients were treated with disease modifying drugs within 6 weeks of referral and $89 \%$ had treatment to target. Patient experience also improved ( $94 \%$ would now recommend the service compared to $76 \%$ prior to the initiative).

The project was a financial success with total savings for the year, accounting for most generous cost estimates, were $£ 136$ 973. In addition, there was a $42 \%$ reduction in biologic use in this group compared to 2015 . These savings are on top of wider economic and societal benefits achieved by inducing low disease activity or remission.

Disclosure of Interest: None declared

DOI: 10.1136/annrheumdis-2018-eular.1329

\section{AB1259 IS DOSE BANDING OF INFLIXIMAB COST EFFECTIVE - RESULTS FROM REAL WORLD IMPLEMENTATION}

\section{M.K. Nisar. Rheumatology, Luton and Dunstable University Hospital, Luton, UK}

Background: Infliximab dose is based on the patient's body weight (3-5 mg/kg) and requires the use of multiple $100 \mathrm{mg}$ vials to reconstitute the individualised dose. As the product is expensive, there is a significant cost associated with unused and wasted infliximab in any part-used vials. "Dose banding" is one solu tion so that patients receive a pre-prepared dose produced in advance in batches where wastage from part vials is minimised. There is some encouraging data that reconstituted infliximab is stable for long enough to allow batch production of preprepared doses. The theoretical risk of course is over or under treatment while respectively rounding up or down the administered dose.

Objectives: We undertook a retrospective analysis of our experience of dose banding in rheumatology unit.

Methods: All patients prescribed infliximab for rheumatic indication at our centre were included in the analysis. Case notes were retrospectively reviewed to look a dose variance following implementation of this initiative, resultant disease contro and the consequent cost savings.

Results: 10 patients prescribed infliximab biosimilar and two bio-originator were identified for the analysis. Median age was 55.5 years (range $25-80$ years). Nine had the drug for RA, two for AS and one for myositis.

Three had no change in dose as a result of implementing dose banding program. Three had dose increased by $3 \%-5 \%$. Remaining six had dose reduced by range of $4 \%-6 \%$. Their disease scores before and after dose banding remained largely unchanged (table 1). This equated to $£ 1,184.58$ annual savings in addition to the economic benefit of successfully switching the ten patients to biosimilar. No patient suffered loss of efficacy or adverse events in any of the three groups.

Conclusions: Our data confirms the utility of dose banding program for infliximab in rheumatology practice with no concerns about efficacy or safety of the initiative. There are potential opportunities to achieve considerable reductions in medicines discarded and improving finances by adopting dose banding for infliximab. It also helped curb over $£ 10000$ expense to our Trust in infliximab waste cost alone. There are some important caveats to consider as well. True savings will depend on list price of each product and varies with originator versus biosimilar. The variance increases as the width of the dose bands increases i.e. the variance is greater at lower body weights. Consequently, depending on patient population both clinical and cost considerations could alter. Finally, assurance of the product

Abstract AB1259 - Table 1

\begin{tabular}{|c|c|c|c|c|c|c|c|c|c|c|}
\hline Age & Sex & Ethnicity & Indication & $\begin{array}{l}\text { Prior dose } \\
\quad(\mathrm{mg})\end{array}$ & $\begin{array}{l}\text { Pre banding } \\
\text { Disease } \\
\text { score }\end{array}$ & $\begin{array}{c}\text { New dose } \\
(\mathrm{mg})\end{array}$ & $\begin{array}{l}\text { Post banding } \\
\text { Disease } \\
\text { score }\end{array}$ & Variance & $\begin{array}{l}\text { Dose } \\
\text { vials }\end{array}$ & $\begin{array}{c}\text { Saving } \\
\text { (12 month) }\end{array}$ \\
\hline 48 & $M$ & Mixed & AS & 400 & 3.2 & 400 & 3.9 & $0 \%$ & 4 & $£ 0.00$ \\
\hline 58 & $\mathrm{~F}$ & White & RA & 210 & 2.3 & 200 & 2.8 & $-5 \%$ & 2 & $£ 87.00$ \\
\hline 54 & $\mathrm{~F}$ & White & RA & 300 & 3.6 & 300 & 1.7 & $0 \%$ & 3 & $£ 0.00$ \\
\hline 44 & $\mathrm{~F}$ & White & RA & 210 & 2.2 & 200 & 1.8 & $-5 \%$ & 3 & $£ 87.00$ \\
\hline 78 & $\mathrm{~F}$ & Asian & RA & 170 & 4.1 & 175 & 3.3 & $3 \%$ & 2 & $-£ 43.50$ \\
\hline 56 & $\mathrm{~F}$ & White & RA & 300 & 2.5 & 300 & 2.1 & $0 \%$ & 2 & $£ 0.00$ \\
\hline 73 & $\mathrm{~F}$ & White & RA & 210 & 3.9 & 200 & 3.9 & $-5 \%$ & 2 & $£ 87.00$ \\
\hline 80 & $\mathrm{~F}$ & White & RA & 190 & 3.8 & 200 & 3.8 & $5 \%$ & 3 & $-£ 87.00$ \\
\hline 49 & $\mathrm{~F}$ & White & RA & 210 & 2.3 & 200 & 3.4 & $-5 \%$ & 3 & $£ 87.00$ \\
\hline 55 & $M$ & White & AS & 320 & 0.2 & 300 & 0.4 & $-6 \%$ & 2 & $£ 174.00$ \\
\hline \multicolumn{11}{|c|}{ Bio-originator } \\
\hline \multicolumn{11}{|c|}{ Patients } \\
\hline 25 & $\mathrm{~F}$ & White & RA & 120 & 4.1 & 125 & 4.1 & $4 \%$ & 0 & $£ 0.00$ \\
\hline 49 & $\mathrm{~F}$ & White & Myositis & 470 & $\begin{array}{c}\text { Well } \\
\text { controlled }\end{array}$ & 450 & $\begin{array}{c}\text { Well } \\
\text { controlled }\end{array}$ & $-4 \%$ & 0 & $£ 793.08$ \\
\hline
\end{tabular}

